\title{
Nematóides das galhas, Meloidogyne spp., associados ao parasitismo de plantas na regiảo amazônica. I - No Estado do Pará.
}

\author{
Francisco das Chagas Oliveira Freire $\left({ }^{\circ}\right)$
}

\begin{abstract}
Resumo
O primeiro levantamento de plantas hospedeiras dos nematóides das galhas, Meloidogyne spp. empreendido em diversos municípios do Estado do Pará, possibilitou catalogar 48 diferentes espécies hospedeiras, entre plantas cultivadas e silvestres. Do total de plantas catalogadas, 22 nảo haviam sido ainda, ao que consta, registradas como hospedeiras dos referidos nematóides. Quatro espécies de nematóides das galhas foram identificadas no curso deste levantamento.
\end{abstract}

\section{INTRODUÇÃO}

Os nematóides causadores de galhas em raízes de plantas, representados pelas espécies filiadas ao gênero Meloidogyne Goeldi 1887, ocasionam graves e freqüentes danos à agricultura nas mais diversas regiõen do mundo. O acendrado polifagismo da maioria de suas espécies, a par da ampla dispersão geográfica alcançada, asseguram a este grupo de fitonematóides uma posição de destaque dentre os mais temiveis patógenos vegetais.

As informaçōes acerca da ocorrência dos nematóides das galhas em plantas da região amazônica são praticamente inexistentes, não obstante já se soubesse do ataque dos mencionados parasitas em algumas culturas da Amazônia. Com efeito, Manço (1973) encontrou em alguns municípios do Estado do Pará mudas de cacaueiro, que exibiam galhas $n_{-}$ raizes, decorrentes do parasitismo por nematóides do gênero Meloidogyne. Lordello \& Silva (1974) no exame de plantas de pimenta do reino, coletadas em Belém, no Instituto cie Pesquisas Agropecuárias do Norte (atual Centro de Pesquisa Agropecuária do Trópico Úmido-EMBRAPA), identificaram a espécie $M$. incognita associada às raizes daquela cultura.

O trabalho em apreço foi elaborado com o intuito de fornecer maiores subsídios ao co- nhecimento das plantas hospedeiras e espécies de nematóides das galhas que ocorrem na região amazônica.

\section{MATERIAL E MÉtodos}

Este levantamento processou-se em diversos municípios do Estado do Pará. As amostras examinadas constituiam-se de piantas cultivadas e silvestres, que exibiam galhas nas raizes. As plantas eram coletadas ao acaso, independente do aspecto vegetativo. O material assim recolhido era preservado em vidros de $150 \mathrm{ml}$, com formalina a $5 \%$, e conduzido ao iavoratório de Fitopatoiogia do Centro de Pesquisa Agropecuária do Trópico Úmido (Belém). oride procediamos à cuidadosa identificação das espécies envolvidas no parasitismo, com base no modelo perineal das fêmeas adultas (Taylor et al., 1955).

A obtenção dos nematóides, a partir das raizes infetadas, e as montagens microscópicas processaram-se segundo as técnicas descritas por Lordello (1964) e Ponte (1968).

Todo o material coletado e preservado em formalina foi incorporado à Coleção Nematológica do Centro de Pesquisa Agropecuárıa do Trópico Úmido.

\section{RESULTADOS E DISCUSSÃO}

Nesta primeira etapa do trabalho, foram catalogadas, nos diversos municípios amostrados, 48 diferentes espécies de plantas hospedeiras de nematóides das galhas.

No Quadro I, encontram-se relacionadas todas estas plantas, bem assim a espécıe ou espécies do parasita que, por ocasião da coleta, as infetavam.

Foram assinaladas, até o momento, no Estado do Pará, quatro espécies do gênero Meloidogyne Goeldi, 1887: M. incognita, M. ja-

(") - Centro de Pesquisa Agropecuária do Tró pico Úmido, Belém. 
vanica, M. arenaria e M. hapla. A primeirz espécie foi identificada em $85 \%$ das plantas cataiogadas, evidenciando uma maior dispersão que as demais. Estes resultados, aliás, assemelham-se aos encontrados por Lordello (1964) em São Paulo e Ponte (1968) no Ceará. Seguiram-se M. javanica e $M$. arenaria, com incidências da ordem de $27 \%$ e $22 \%$ respectivamente. A espécie $M$. hapla foi assinalada em uma única oportunidade no curso do levantamento. Neste trabalho, não consideràmos, separadamente, a variedade $M$. incognita acrita, a qual é aqui sinonimizada com $M$. in. cognita.

Com relação ao aspecto nematológico, o presente levantamento oferece interessantes informações quanto à lista de hospecieiros dos nematóides em questão. Com efeito, dentre as 48 espécies vegetais catalogadas, 22 não foram ainda, ao que consta, referidas como hospedeiras dos nematóides das galhas (segundo o catálogo organizado por Goodey, Franklin \& Hooper, 1965). Assim, Piatonia insignis (bacuri), Piper umbellata (capeba), Bidens cynapiifolia (carrapicho de agulha) Renealmia sp. (Cardamomo), Crataeva tapia (catauari), Amaranthus gracilis (caruru do sul), Solanum toxicarium (jurubeba), Vismia guianensis (lacre), Melothria sp. (Melancia de rato), Pogostemon heyneanus (oriza), Piper aduncum (Pimenta longa), Piper columbrium (pimenta longa), Couma guianensis (sorveira), Chelonanthus chelonoides (tabaco bravo), Tephrosia nitens (timbó). Miconia minutiflora (tinteiro branco), Pterolepsis trichotoma (viuvinha), Borreria latifolia, Melochia melissaefolia, Rolandra fruticosa, Cyathula prostrata e Sparganophorus vaillantii ingressam na ìteratura nematológica como novos hospedeiros. Incluemse também, na citada lista, piantas que, embora já referidas como hospedeiras dos nematóides das galhas, são relacionadas, pela primeira vez, como hospedeiras de outras espé. cies deste grupo de nematóides. A guisa de exemplo, podem ser citadas: Codiaeum variegatum pictum (cróton variegado) e Cleomo aculeata panasitados por $M$. incognita e Arto. carpus integrifolia (jaqueira) parasitada po: M. javanica. A exceção de Piper nigrum (Pimenta do reino), a qual já havia sido referida por Lordello \& Silva (1974) como hospedeiro de M. incognita no Estado do Pará, todas as demais plantas relacionadas no Quadro I são, pela primeira vez, assinaladas como hospedeiras destes nematóides na região amazônica.

Do ponto de vista econômico, os dados obtidos no presente levantamento demonstram a ocorrência de espécies de nematóides das gaihas associadas ao parasitismo de diversas culturas de interesse econômico para a Amazônia. Deve-se atender também para a elevada incidência destes nematóides em espécies silvestres, na maioria dos casos, naqueias mais difundidas nas áreas agrícolas regionais. As plantas referidas atuam como fonte de multiplicação para os nematóides deste grupo, em detrimento de uma exploração agrícola bem sucedida. A lista de plantas exposta no Quadro I, além de demonstrar o acendrado polifagismo das espécies de nematóides das galhas identificadas, poderá fornecer, no futuro, subsídios à elaboração de um plano para o controle dos mencionados nematóides.

\section{CoNCLusões}

Muito embora os resultados expostcs no Quadro I constituam apenas a primeira etapa deste levantamento, interessantes conclusões podem ser fornecidas com base naqueles dados :

a - A ampla dispersão geográfica já alcançada pelos nematóides das galhas, a par das repetidas incidências em culturas de interesse econômico, demonstram que tais parasitas poderão vir a se constituir num dos mais sérios problemas agrícolas para o Estado do Pará, bem assim para toda a região amazônica;

b - Dentre as quatro espécies de Meloidogyne identificadas no Estado do Pará, M. incognita mostra-se, até o momento, como a mais dispersa, ocorrendo em $85 \%$ das espécies vegetais catalogadas. Seguem-na, com menores incidências, as espécies $M$. javanica e $M$. arenaria com $27 \%$ e $22 \%$, respectivamente. Em plano de menor expressão, encontra-se $M$. hapla, identificada em uma única oportunidade como parasita de raízes de juta; 
QUADRO I - Relação das plantas hospedeiras dos nematóides das galhas, Meloidogyne spp., catalogadas no Estado do Pará.

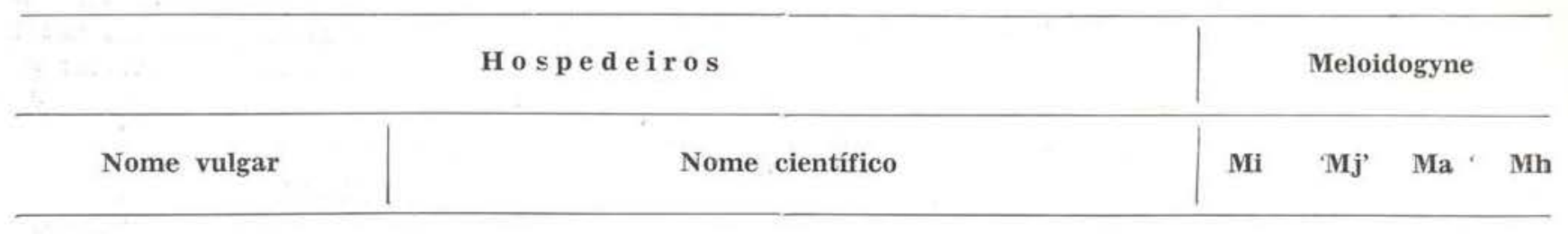

\begin{tabular}{|c|c|c|c|c|c|}
\hline Abóbora & Cucurbita pepo L. & $\mathrm{X}$ & & & \\
\hline Alface & Lactuca sativa $\mathrm{L}$. & $\mathrm{X}$ & & & \\
\hline Bacurizeiro & Platonia insignis Mart. & $\mathrm{X}$ & & $\mathrm{x}$ & \\
\hline Bananeira & Musa sp. & $\mathrm{x}$ & & & \\
\hline Beldroega & Portulaca oleracea L. & $\mathrm{X}$ & & & \\
\hline Cacaueiro & Theobroma cacao L. & $\mathrm{x}$ & & $\mathrm{x}$ & \\
\hline Capeba & Piper umbellata H.B.K. & $\mathrm{X}$ & & & \\
\hline Carrapicho de agulha & Bidens cynapiifolia H.B.K. & & $\mathrm{X}$ & & \\
\hline Cardamomo & Renealmia sp. & $\mathrm{x}$ & & & \\
\hline Caruru do sul & Amaranthus gracilis Desf. & $\mathrm{x}$ & & & \\
\hline Catauary & Crataeva tapia L. & $\mathrm{x}$ & & & \\
\hline Cravo da fndia & Eugenia caryophyllata Thunb. & $\mathrm{x}$ & & & \\
\hline Crótcn variegado & Codiaeum variegatum Bl. pictum Muell Arg. & $\mathrm{x}$ & & $\mathrm{X}$ & \\
\hline Feijoeiro comum & Phaseolus vulgaris $\mathrm{L}$. & & $\mathrm{x}$ & & \\
\hline Guaraná & Paullinia cupana H.B.K. var. sorbilis (Mart.) Ducke & $\mathrm{x}$ & $\mathrm{x}$ & & \\
\hline Jaqueira & Artocarpus integrifolia $\mathrm{L}$. & & $\mathrm{X}$ & & \\
\hline Jerimum & Cucurbita maxima Duch. & $\mathrm{x}$ & & & \\
\hline Jurubeba & Solanum toxicarium Rich. & $\mathrm{x}$ & $\mathrm{X}$ & & \\
\hline Juta & Corchorus capsularis L. & $\mathrm{x}$ & $\mathrm{x}$ & & $\mathrm{x}$ \\
\hline Lacre & Vismia guianensis (Aubl.) Choisy & & $\mathrm{x}$ & $\mathrm{x}$ & \\
\hline Malva & Urena lobata $\mathrm{L}$. & $\mathrm{x}$ & & $\mathrm{x}$ & \\
\hline Mamoeiro & Carica papaya $\mathrm{L}$. & $\mathrm{x}$ & & & \\
\hline Mandioca & Manihot esculenta Crantz & $\mathrm{x}$ & & & \\
\hline Melancia de rato & Melothria sp. & $\mathrm{x}$ & & & \\
\hline Melão & Cucumis melo $\mathrm{L}$. & & $\mathrm{x}$ & & \\
\hline Oriza & Pogostemon heyneanus Berth. & $\mathrm{x}$ & & $\mathrm{x}$ & \\
\hline Paramarioba & Cassia occidentalis $\mathrm{L}$. & $\mathrm{x}$ & $\mathrm{x}$ & & \\
\hline Pimenta longa & Piper aduncum L. & $\mathrm{x}$ & & & \\
\hline Pimenta longa & Piper columbrinum Link. & $\mathrm{x}$ & & $\mathrm{x}$ & \\
\hline Pimenta malagueta & Capsicum fructescens Wilid. & & $\mathrm{X}$ & & \\
\hline Pimenta murutucu & Piper sp. & & & $\mathrm{x}$ & \\
\hline Pimenta-do-reino & Piper nigrum $L$. & $\mathrm{x}$ & & $\mathrm{x}$ & \\
\hline Puerária & Pueraria phaseoloides Benth. & $x$ & & & \\
\hline Quiabeiro & Hibiscus esculentus L. & $\mathrm{x}$ & & & \\
\hline Seringueira & Hevea brasiliensis Muell. Arg. & $\mathrm{x}$ & $\mathrm{x}$ & $\mathrm{x}$ & \\
\hline Sorveira & Couma guianensis Aubl. & & & $\mathrm{X}$ & \\
\hline Tabaco bravo & Chelonanthus chelonoides (LF) Gilg. & $\mathrm{x}$ & $\mathrm{x}$ & & \\
\hline Taperebazeiro & Spondias lutea $\mathrm{L}$. & $\mathrm{X}$ & & & \\
\hline Timbó & Tephrosia nitens Benth. & $\mathrm{x}$ & & & \\
\hline Tinteiro branco & Miconia minutiflora (Bompl.) DC. & $\mathrm{x}$ & & & \\
\hline Tomateiro espontâneo & Lycopersicum sp. & $\mathrm{x}$ & & & \\
\hline Viuvinha. & Pterolepis trichotoma (Rottb.) Cogn. & $\mathrm{x}$ & & & \\
\hline & Borreria latifolia (Aubl.) K. Schum. & $\mathrm{x}$ & & & \\
\hline$\longrightarrow$ & Cleome aculeata $\mathrm{L}$. & $\mathrm{x}$ & & & \\
\hline & Melochia melissaefolia Benth. & $\mathrm{x}$ & & & \\
\hline$\longrightarrow$ & Rolandra fruticosa (L.) Kuntze & $\mathrm{x}$ & & & \\
\hline$\longrightarrow$ & Cyathula prostrata (L.) Blume & $\mathrm{x}$ & & & \\
\hline$\longrightarrow$ & Sparganophus vaillantii Crantz. & $\mathrm{x}$ & & & \\
\hline
\end{tabular}


c - Das 48 plantas catalogadas como hospedeiras dos nematóides das galhas, 22 são registradas pela primeira vez como tal. A despeito das inúmeras plantas de interesse econômico parasitadas por nematóides deste grupo, não se pode desprezar o fato de algumas plantas silvestres estarem incluídas nesta lista, as quais contribuem, sobremaneira, para elevar ainda mais a população nêmica do solo.

\section{SUMMARY}

The survey of host plants of the root-knot nematodes, Meloidogyne spp., undertaken in several countries of the State of Para, Brazil, made it possible to catalog 48 different host species among cultivated and wild plants. Between the 48 host plants listed in this report, that is the first time that twenty-two of them have been reported as hosts of the root-knot nematodes.

The root-knot nematodes $\mathbf{M}$. incognita, M. javanica, M. arenaria and $\mathbf{M}$. hapla were the parasites found in this survey.

\section{BIBLIGGRAFIA CITADA}

LORDELLO, L.G.E.

1964 - Contribuição ao conhecimento dos nematóides que causam galhas em raizes de plantas em São Paulo e Estados vizinhos An. Esc. Sup. Agric., "Luiz de Queiroz", 21 : 181-218.

LORDELLO, L.G.E. \& SILVA, H.M.

1974 - Um nematóide nocivo à pimenta-do-reino. Rev. Agric., Piracicaba, 49 (4): $165-66$.

MANço, G.R.

1973 - Considerações gerais sobre as enfermidades do cacaueiro na Amazônia. Rev. Theobroma, 3(1) : 3-13.

PONTE, J.J, DA

1968 - Subsídios ao conhecimento de plantas hospedeiras e ao controle dos nematóides das galhas, Meloidogyne spp. no Estado do Ceará (Tese de M.S.) Bol. Soc. Cear. Agron., 9: 1-26.

TAYLoR, A. L.; Dropkin, V.H. \& MARTIN, G. C. 1955 - Perineal patterns of root-knot nematodes. Phytopathology, 45(1) : 26-34. 